\title{
NILAI-NILAI KEPAHLAWANAN TOKOH I GUSTI KETUT JELANTIK DALAM PERANG JAGARAGA (1846-1849) SEBAGAI SUMBER PENANAMAN KARAKTER DALAM PEMBELAJARAN IPS DI SMP LABORATORIUM UNDIKSHA SINGARAJA
}

\author{
Putu Wusantria Widya Asih"1, ${ }^{*}$ I Wayan Kertih², Tuty Maryati ${ }^{3}$ \\ 1 Universitas Pendidikan Ganesha \\ 2 Universitas Pendidikan Ganesha \\ 3 Universitas Pendidikan Ganesha
}

\begin{abstract}
Abstrak
This research aimed to 1) know the biography of I Gusti Ketut Jelantik in Jagaraga's War; (2) analyze the character value of I Gusti Ketut Jelantik's heroism in Jagaraga's War; (3) analyze the integration of I Gusti Ketut Jelantik's heroism value as a source of character building in IPS study in SMP Laboratorium Undiksha Singaraja. This research used qualitative research method with: the location of this research is in monument of Jagaraga's war, Puri Kanginan Buleleng, SMP Laboratorium Undiksha Singaraja, Puri Agung Karangasem, and LVRI Bali; the method to determine an informant is use purposive sampling; the data was collected by observation, interview, and document study; the instrument is use the line of interview to collect the data with camera, audio recorder, and manual recording as a support; the method the to examine the real data is us three methods: theory triangulation or source data, method triangulation, and theory triangulation; the analysis method in this research is use data reduction, data presentation, and drag the conclusion or verification. The result from this research shows the biography of I Gusti Ketut Jelantik or more famous with Patih Jelantik who become the "Patih Jelantik" in Buleleng Kingdom who also dead in Jagaraga's war in 1849. The values from I Gusti Ketut Jelantik are: religious, honest, tolerant, hard worker, creative, love the nation, kindly, merciful, and responsible. The integration from the values of I Gusti Ketut Jelantik heroism are made by adding the value of him into the indicator in IPS syllabus, and integrated it in RPP and study lesson.
\end{abstract}

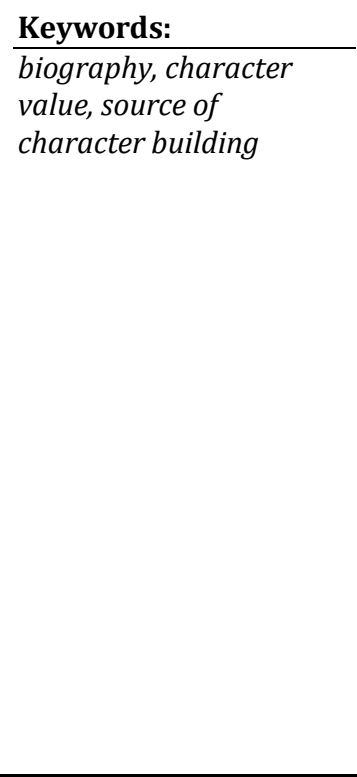

\section{PENDAHULUAN}

Globalisasi merupakan sebuah fakta yang tidak bisa diingkari. Dampak dari globalisasi dapat dilihat dari segi positif dan negatif. Kerusakan moral remaja yang saat ini marak terjadi merupakan dampak negatif dari adanya globalisasi. Kerusakan karakter generasi muda saat ini juga bisa dibuktikan dari munculnya kepermukaan sebuah kenyataan miris yaitu terjadinya kenakalan remaja diluar batas kewajaran. Langkah yag bisa diambil dalam menghadapi globalisasi ini, salah satunya adalah memperkokoh karakter generasi bangsa khususnya anak-anak muda melalui pendidikan baik pendidikan formal maupun secara nonformal. Pendidikan adalah proses pengubahan sikap dan tata laku seseorang atau kelompok orang dalam usaha mendewasakan manusia melalui upaya pengajaran dan pelatihan, proses, cara, perbuatan mendidik (Pusat Bahasa Departemen Pendidikan Nasional, 2002: 263).

Tujuan pendidikan nasional merupakan rumusan mengenai kualitas manusia Indonesia yang harus dikembangkan oleh setiap satuan pendidikan. Dalam membentuk sebuah kepribadian yang baik, tidak bisa dilepaskan dari pendidikan IPS. Hal ini dikarenakan pendidikan IPS memiliki tujuan, fungsi serta peran dalam meningkatkan sumber daya manusia untuk memperoleh bekal pengetahuan tentang harkat dan martabat manusia sebagai makhluk sosial, ketrampilan menerapkan pengetahuan tersebut dan mampu bersikap berdasarkan nilai dan norma sehingga mampu hidup bermasyarakat. Pembelajaran IPS sebagai salah satu mata pelajaran wajib di tingkat SMP memiliki tujuan yang sangat strategis dalam 
kaitannya dalam pembentukan dan pembangunan warga negara yang berkualitas. Tujuan pendidikan IPS ini sejalan dengan pendidikan karakter, dengan sejalnnya tujuan yang akan dicapai maka dalam kegiatan pembelajaran akan mengalami kesinambungan satu sama lain. Namun, pada kenyataannya pengayaan materi pembelajaran dalam pembelajaran IPS saat ini masih kurang efisien sebab yang dijadikan patokan oleh guru hanya sebatas materi ajar yang terdapat di dalam buku pelajaran.

Salah satu upaya yang dapat dilakukan untuk memperbaiki karakter generasi muda saat ini adalah menggali kembali nilai-nilai karakter yang terdapat dalam jiwa pahlawan. Nilai karakter yang terdapat pada diri pahlawan dapat menjadi cerminan dan tolak ukur terhadap generasi muda saat ini. Salah satu pahlawan nasional yang berasal dari Bali ialah I Gusti Ketut Jelantik. I Gusti Ketut Jelantik merupakan salah satu dari sekian banyak para pejuang kemerdekaan Indonesia yang seakan-akan terlupakan oleh para generasi muda Bali, khususnya oleh kaum terpelajar yang tidak mengetahui secara jelas siapa sosok pahlawan I Gusti Ketut Jelantik sebenernya. Nama I Gusti Ketut Jelantik juga mendapat perhatian dan apresiasi di Kabupaten Badung. Sebagai bukti, nama I Gusti Ketut Jelantik diabadikan sebagai salah satu nama jalan di Kabupaten Badung yaitu jalan I Gusti Ketut Jelantik yang terletak di seputaran Mengwi. Namun, setelah dilakukan wawancara dengan masyarakat sekitar jalan I Gusti Ketut Jelantik ternyata masyarakat tersebut tidak mengenal siapa I Gusti Ketut Jelantik.

Di SMP Laboraorium Undiksha Singaraja juga dilakukan penelitian terhadap siswa mengenai pahlawan I Gusti Ketut Jelantik. Ternyata setelah dilakukan wawancara sebagai besar siswa pernah mendengar nama I Gusti Ketut Jelantik tetapi tidak mengetahui secara rinci mengenai kisah perjuangan I Gusti Ketut Jelantik. SMP Laboratorium Undiksha Singaraja merupakan sekolah swasta yang selalu mengedepankan kedisiplinan. Saat ini di SMP Laboratorium Undiksha Singaraja sudah dilakukan usaha penanaman nilai karakter kepada siswanya. Namun, penanaman nilai karakter yang diberikan masih belum maksimal. Model penanaman nilai karakter yang diberikan masih berupa teori yang hanya tercetak pada RPP guru saja. Dalam pembelajaran IPS di SMP Laboratorium Undiksha Singaraja, guru masih sebatas memberikan materi yang terdapat dalam buku ajar dan terpatok pada silabus pegangan. Sebenarnya, materi ajar IPS yang terdapat dalam buku ajar masih dapat dikembangkan dengan melihat keadaan lingkungan sekitar. Salah satunya adalah pemberian contoh dalam materi ajar sejarah di IPS adalah pengembangan sejarah lokal.

Salah satu sejarah lokal adalah sejarah Perang Jagaraga yang dipimpin oleh I Gusti Ketut Jelantik. Sejarah lokal tersebut dapat menjadi pengayaan materi pembelajaran dalam pembelajaran IPS. Langkah yang perlu dilakukan yaitu dengan menggunakan nilai-nilai kepahlawanan dari tokoh I Gusti Ketut Jelantik sebagai sumber penanaman karakter dengan cara memilih materi yang ada pada KD (Kompetensi Dasar) IPS untuk SMP pada silabus KTSP. Khusus untuk tokoh I Gusti Ketut Jelantik sangat cocok diterapkan di kelas VIII pada KD 5.2 yaitu mendeskripsikan peristiwa-peristiwa sekitar proklamasi dengan materi pokok pembelajaran dukungan spontan terhadap Proklamasi dan tindakan heroik di berbagai daerah. Dari aspek yang tercantum di dalam Kurikulum KTSP di SMP Laboratorium Undiksha kelas VIII semester genap, nilai karakter I Gusti Ketut Jelantik yang dikembangkan digunakan sebagai pengayaan materi pembelajaran sangat sesuai dengan materi pokok pembelajaran di dalam Kurikulum KTSP di SMP Laboratorium Undiksha kelas VIII semester genap.

Penelitian ini bertujuan untuk memahami riwayat hidup dari tokoh I Gusti Ketut Jelanti dalam Perang Jagaraga, menganalisis nilai-nilai karakter yang terdapat dalam kepahlawanan tokoh I Gusti Ketut Jelantik dalam perang Jagaraga, dan menganalisis pengintegrasian nilai-nilai kepahlawanan tokoh I Gusti Ketut Jelantik dalam perang Jagaraga sebagai sumber penanaman karakter dalam pembelajaran IPS di SMP Laboratorium Undiksha Singaraja. Kajian teori yang digunakan dalam penelitian ini menyangkut hakekat karakter, hakekat pembelajaran IPS, pahlawan sebagai nilai karakter dan kajian biografi.

\section{METODE PENELITIAN}

Metode penelitian yang digunakan dalam penelitian ini adalah metode penelitian kualitatif. Metode kualitatif diantaranya terdapat (1) metode penentuan lokasi penelitian. Lokasi penelitian dalam penelitian ini adalah Monumen Perang Jagaraga, Puri Kanginan Buleleng, SMP Laboratorium Undiksha, Puri Agung Karangasem dan LVRI daerah Bali. (2) metode penentuan informan. Informan yang dituju untuk memperoleh data yaitu A.A. Ngurah Parwata Panji, .A Gede Putra Agung, Djero Wiladja, Made Kondra dan I Gusti Bagus Saputera. (3) metode pengumpulan data dalam penelitian ini adalah observasi, wawancara dan studi dokumen. (4) metode pengujian kesahihan data dalam penelitian ini adalah triangulasi data atau triangulasi sumber data, triangulasi metode, dan triangulasi teori. (5) metode analisis data dalam penelitian ini mencakup tiga kegiatan bersamaan yang meliputi: reduksi data, penyajian data, penarikan kesimpulan atau verifikasi. 


\section{ANALISIS DAN PEMBAHASAN}

I Gusti Ketut Jelantik atau lebih dikenal dengan Patih Jelantik merupakan Patih Agung kerajaan Buleleng, yang gugur dalam perang Jagaraga tahun 1849. Dalam buku Perang Jagaraga (Soegianto, 2011: 11) dijelaskan bahwa I Gusti Ketut Jelantik adalah putra ketiga dari seorang bangsawan Buleleng yang sebelum pindah ke Puri Kanginan Buleleng bermukim di Kubutambahan di lingkungan Punduh Puri. Ayah dari I Gusti Ketut Jelantik adalah Ki Gusti Anglurah Ketut Jelantik, salah seorang keturunan Raja Buleleng dari wangsa Panji Sakti yang telah diturunkan kekuasaannya oleh penguasa Karangasem yang mendominasi kerajaan Buleleng.

I Gusti Ketut Jelantik memiliki seorang istri yang bernama Jempiring. Patih Jelantik berjumpa dengan istrinya jempiring yang tingal di sekitar Punduh Puri Kubutambahan. Versi Punduh Puri tentang asal Jero Jempiring juga sangat memperkuat dugaan I Gusti Ketut Jelantik berasal dari klan Panji Sakti. Karena tempat yang bernama Punduh Puri di Kubutambahan dahulunya adalah tempat pemukiman bangsawan-bangsawan Buleleng yang mengabdi kepada raja-raja Karangasem sejak zaman Anak Agung Pahang, yang tentunya pernah menjadi tempat kediaman orang tua atau kakek I Gusti Ketut Jelantik.

Latar belakang terjadinya Perang Buleleng dan Perang Jagaraga adalah pada tahun 1844 terjadi perampasan terhadap kapal-kapal yang rusak atau karam di pantai Sangsit dan pantai Perancah di wilayah Jembrana. Gagasan ini diperkuat Soehartono dalam Perang Jagaraga (1973: 211), kejadian ini merupakan rangkaian sebab terjadinya Perang Buleleng dan Perang Jagaraga yaitu sebagai bukti keberanian rakyat Bali mempertahankan adat agar undang-undang tawan karang tetap dijalankan. Jika dilihat dari sudut pandang ekonomi, hak tawan karang ini merupakan peraturan yang menguntungkan kepada masyarakat pesisir. Pada tahun 1844 terjadi dua perampasan atas dua kapal yang terdampar di pantai Sangsit wilayah Buleleng dan di Perancah wilayah Jembarana. Jika dikaji dari sudut pandang Geografi, jalur perairan yang terdapat di selat Bali adalah jalur yang strategis dan aman. Oleh karenanya jalur pelayaran ini ramai dilewati, dan itulah yang menyebabkan banyaknya kapal yang terdampar.

Awal perang Buleleng dimulai saat Residen Besuki Maijor datang sendiri ke Bali pada bulan Mei 1845 untuk meratifisir perjajian penghapusan tawan karang. Permintaan Maijor tersebut ditolak oleh raja Buleleng dan penolakan ini adalah salah satu sebab terjadinya perang antara kerajaan Buleleng dengan pemerintah Hindia Belanda. Oleh raja Buleleng persoalan di atas diserahkan kepada patih Buleleng Gusti Ketut Jelantik. Setelah ketentuan-ketentuan itu dibaca, Gusti Jelantik sangat marah dan menghina utusan Belanda yang pada waktu itu menghadap raja Buleleng dengan kata-kata pedas. Setelah utusan Belanda itu mendengar kata-kata Gusti Jelantik, maka ia segera melaporkan kepada Gubernur Jenderal di Batavia.

Raja Buleleng dengan patihnya tahu bahwa Belanda akan menyerang. Segala keperluan perang telah disiapkannya. Soehartono dalam Perang Jagaraga (1973: 215), menyatakan pasukan Belanda mendarat di pantai Buleleng pada tanggal 24 Juni 1846. Tanggal 29 Juni, sebelum matahari terbit pasukan Belanda bergerak kearah Singaraja. Prajurit Bali makin terdesak, pertahanan mereka bertambah kacau. Pasukan Buleleng dan orang-orang Bugis mundur sambil bertahan. Rumah-rumah penduduk telah ditinggalkan dan puri Singaraja dibakar habis.

Hal ini diperkuat dari hasil buku Perang Jagaraga, Soegianto (2011: 52) menyatakan bersama dengan jatuhnya Kerajaan Buleleng ke tangan Belanda setelah Perang Buleleng pada bulan Juni 1846, atas desakan patih I Gusti Ketut jelantik, raja Buleleng memutuskan untuk mengundurkan diri. Bersama-sama dengan laskar dan rakyat yang masih setia raja dan patih Jelantik mengundurkan diri kearah timur dengan tujuan desa Jagaraga. Tanggal 9 Juli 1845 Buleleng dan Karangasem menandatangani perjanjian baru dengan Belanda. Untuk merahasiakan rencana konsulidasi, Patih Jelantik menyetujui taktik rajanya I Gusti Ngurah Made Karangasem untuk mengadakan perjanjian penyerahan terhadap pemerintah kolonial Belanda. Patih Jelantik bermaksud mempergunakan perjanjian ini untuk merealisasikan rencananya dan pada satu saat akan memukul dan mengusir Belanda dari wilayah kerajaan Buleleng.

Patih Jelantik secara rahasia telah mengirimkan mata-mata untuk mengetahui kegiatan serdadu Belanda di Pabean dan kemudian mengambil kesimpulan bahwa Belanda telah mempersiapkan suatu penyerangan besar-besaran terhadap Jagaraga. Karena itu patih Jelantik memutuskan lebih memperkuat Jagaraga, baik dalam sistem perbentengannya maupun kekuatan laskar dan persenjataannya. Untuk menambah kekuatan laskarnya, patih Jelantik mengirim utusan kepada raja Klungkung sebagai susuhunan raja-raja di Bali dan kepada raja-raja sahabatnya. Utusan yang menghadap kepada raja Klungkung dipimpin langsung oleh patih I Gusti Ketut Jelantik. sebagai pimpinan tertinggi adalah patih I Gusti Ketut Jelantik, sebagai pemegang komando dan Kepala strategi. Walaupun menurut strukur pemerintahan kerajaan Buleleng yang memegang puncak kekuasaan adalah raja Buleleng, tetapi dalam praktek pemerintahan kekuasaan militer serta keputusan peperangan, sepenuhnya berada di 
tangan Patih I Gusti Ketut Jelantik. Untuk mengimbangi kekuatan Belanda ini, patih Jelantik telah memilih sistem pertahanan supit urang (makara wyuha).

Pada tahun1847 di pantai Kusamba dan Badung terdampar kapal yang tidak jelas kebangsaannya. Penumpang serta muatan dikenakan tawan karang. Kejadian ini dipakai alasan oleh Belanda untuk melakukan perang yang kedua kalinya, disamping alasan-alasan lain karena Buleleng dan Karangasem tidak menepati perjanjian yang pernah dibuat. Perang tahun 1848 ini disebut Perang Jagaraga I. Menurut Soegianto dalam Perang Jagaraga (2011: 125) menyatakan, pada tanggal 9 Juni 1848, devisi Mayoor Sorg berusaha menguasai Bungkulan menuju desa Jagaraga dan bermaksud memukul langsung pusat pertahanan patih Jelantik. Hal senada juga dinyatakan Soehartono dalam Perang Jagaraga (1973: 220), pada jarak $600 \mathrm{~m}$ kelihatan 2 buah benteng besar, yaitu benteng II dan IV. Benteng-benteng itu adalah benteng tertutup. Soehartono dalam Perang Jagaraga (1973: 221) menyatakan, Laskar Jagaraga lalu mundur melewati lorong rahasia menuju benteng yang ke dua yang terletak dibagian Timur, yang merupakan benteng supit sebelah kanan. Pada benteng kedua ini terjadi lagi pertempuran sengit. Hal ini dibuktikan dari buku Soegianto dalam Perang Jagaraga (2011: 226), menyatakan Belanda berhasil menduduki benteng kedua ini dengan pengorbanan yang besar diantaranya gugur seorang perwira Belanda bernama Kapten Dostal. Belanda tidak menyadari bahwa mundurnya pasukan Jagaraga dari ke dua benteng ini hanya merupakan taktik pancingan.

Pasukan Belanda yang sudah memasuki benteng utama Jagaraga terjebak di depan benteng. Laskar Jagaraga yang berada dalam benteng utama segera menyerbu Belanda beramai-ramai. Van Swieten memerintahkan seluruh pasukannya agar mengundurkan diri dan kembali ke kapal. Patih Jelantik, panglima tertinggi laskar Bali, segera saja dapat melihat perubahan yang mendadak dari situasi medan ini, tidak menunggu lama ia memerintahkan kepada satuan-satuan pilihannya yaitu infanteri Buleleng, Karangasem dan Klungkung yang ada di sektor tengah dan benteng III untuk turun mengejar satuansatuan Belanda yang mengundurkan diri itu, diikuti oleh satuan-satuan Gianyar dan Mengwi dari sektor barat. Masih oleh buku Soegianto dalam Perang Jagaraga (2011:226), hari itu pada tanggal 9 Juni 1848, sisa-sisa serdadu Belanda berhasil mencapai pantai desa Sangsit dan langsung menuju ke kapal. Patih Jelantik tidak pernah menerangkan secara rasional keputusannya untuk membiarkan saja pengunduran diri tentara Belanda sampai mereka kembali ke kapalnya. Kemenangan laskar Jagaraga dalam perang Jagaraga I ini dikarenakan persatuan dan kesatuan antara laskar Jagaraga dengan laskara bantuan dari kerajaan-kerajaan lain seperti laskar Klungkung, Gianyar, Karangasem dan Mengwi. Kepemimpinan Patih I Gusti Ketut Jelantik yang diakui dan ditaati oleh seluruh laskar.

Belanda berusaha mengirim ekspedisi yang ketiga pada awal tahun 1849. Ekspedisi tentara Belanda ini disebut Perang Jagaraga II. Soehartono dalam Perang Jagaraga (1973: 224) menyatakan rajaraja Bali mulai bersiap-siap menghadapi Belanda. Pusat-pusat pertahanan diperbaiki dan diperkuat. Rintangan-rintangan untuk menghambat gerakan pasukan Belanda dipasang. Masih dinyatakan oleh Soehartono dalam Perang Jagaraga (1973: 226), yaitu iring-iringan kapal ekspedisi berangkat dari Batavia, Semarang dan Surabaya dan pada tanggal 28 Maret 1849 telah merapat di pantai Buleleng dan Sangsit. Pasukan Jenderal Michiels sendiri mendarat di Sangsit dan dengan cepat menguasai Sangsit. Adanya dua pendaratan ini telah mengacaukan konsentrasi strategi patih Jelantik dalam menentukan strategi pertahanannya. Pada tanggal 2 Mei tengah hari Letnan Kolonel de Brauw menduduki Buleleng dan dengan bantuan beberapa perwira lainnya mengadakan stelling terhadap Singaraja.

Pada tanggal 13 April datang utusan raja menemui Michiels dan bersedia memenuhi perjanjian yang pernah dibuat. Michiels menuntut agar benteng Jagaraga dirombak sebelum tanggal 15. Apabila pada tanggal yang telah ditetapkan itu benteng Jagaraga belum dirombak, Belanda akan melakukan penyerangan. Tetapi sampai tanggal yang telah ditentukin raja Buleleng dan Karangasem tidak memenuhi perjanjian tersebut. Akhirnya, penyerangan pun dilakukan oleh Belanda, dalam penyerangan tanggal 15 April itu angkatan perang Belanda dibagi menjadi 3 kolone. Soegianto dalam Perang Jagaraga (2011: 202) menyatakan, laskar yang berada dibawah pimpinan patih Jelantik makin terjepit diantara benteng induk dengan lambung kiri. Patih Jelantik dan seluruh pasukannya mendapat serangan yang bertubi-tubi dari arah depan dan dari arah belakang oleh serdadu Belanda. Patih Jelantik tidak mendapat kesempatan untuk memberikan bantuan kepada laskar yang mempertahankan benteng induk. Patih Jelantik memutuskan untuk mengarahkan pasukannya menghadapi pasukan Jenderal Michiels. Patih Jelantik mendapat kesempatan mundur dan bersama-sama dengan raja Buleleng I Gusti Ngurah Made Karangasem berhasil meloloskan diri menuju ke timur dengan tujuan wilayah kerajaan Karangasem. Tanggal 16 April 1849 adalah hari jatuhnya benteng Jagaraga ke tangan Belanda. Kekalahan laskar Jagaraga dikarenakan persenjataan laskar Bali jauh lebih rendah dari segi jumlah maupun kualitas bila dibandingkan dengan persenjataan Belanda dan setelah kemenangan dalam perang Jagaraga I pada tahun 1848 patih Jelantik kurang mengadakan pembinaan wilayah terutama wilayah yang merupakan sayap perbatasan yang menjadi wilayah kontak senjata terutama desa Sangsit yang terletak di pantai. 
Salah satu pahlawan yang dianggap memiliki karakter yang kuat dan dapat dijadikan panutan oleh generasi muda saat ini yaitu I Gusti Ketut Jelantik. I Gusti Ketut Jelantik merupakan pahlawan lokal Bali yang berjuang dalam perang Jagaraga. Beberapa nilai karakter yang terdapat pada sosok pahlawan I Gusti Ketut jelantik antara lain: Religius, Jujur, Toleransi, Kreatif, Bersahabat, Cinta damai, Kerja keras, Semangat kebangsaan, Cinta tanah air, dan Bertanggung jawab.

Nilai-nilai kepahlawanan tokoh I Gusti Ketut Jelantik dapat dijadikan sebagai sumber penanaman karakter dalam pembelajaran IPS berdasarkan Kurikulum Tingkat Satuan Pendidikan (KTSP) dan nilai-nilai kepahlawanan tersebut, dapat dikaitkan pada ranah pembelajaran kognitif dan afektif. Pada ranah kognitif siswa diharapkan mampu memahami, mengaplikasi, menganalisis dan kemampuan mengevaluasi tentang materi peranan I Gusti Ketut Jelantik dalam perang Jagaraga sesuai dengan Kompetensi Dasar (KD) yaitu "mendeskripsikan peristiwa-peristiwa sekitar Proklamasi" dengan materi pokok pembelajaran "dukungan spontan terhadap Proklamasi dan tindakan heroik diberbagai daerah".

Pada ranah afektif diharapkan peserta didik tidak hanya mempelajari dan memahami materi tentang Peranan I Gusti Ketut Jelantik dalam perang Jagaraga tetapi peserta didik juga harus mempelajari dan memahami nilai-nilai kepahlawanan I Gusti Ketut Jelantik, seperti: Religius, Jujur, Toleransi, Kreatif, Bersahabat, Cinta damai, Kerja keras, Semangat kebangsaan, Cinta tanah air, dan Bertanggung jawab agar peserta didik dapat meneladani nilai-nilai tersebut di tegah-tengah terjadinya krisis nilai-nilai moral dan kesadaran etika. Untuk bisa menyampaikan materi dengan baik mengenai nilai-nilai kepahlawanan tersebut dalam proses pembelajaran, maka harus terlebih dahulu di integrasikan ke dalam silabus dan RPP, karena silabus dan RPP merupakan acuan guru dalam merencanakan pelajaran yang akan diberikan kepada peserta didik. Guru dituntut untuk lebih kreatif dalam menyampaikan materi kepada peserta didik agar maksud dan tujuan pembelajaran IPS dapat tersampaikan dengan baik. Begitu pula dengan penjabaran nilai-nilai kepahlawanan di balik sosok I Gusti Ketut Jelantik.

\section{KESIMPULAN}

Berdasarkan hasil penelitian maka dapat disimpulkan bahwa Riwayat hidup I Gusti ketut Jelantik atau yang lebih dikenal Patih Jelantik merupakan patih agung Kerajaan Buleleng yang gugur dalam perang Jagaraga pada tahun 1849. Terdapat beberapa nilai-nilai karakter pada pahlawan I Gusti Ketut Jelantik yakni; nilai religius, jujur, toleransi, kerja keras, kreatif, semangat kebangsaan, cinta tanah air, bersahabat atau komunikatif, cinta damai dan bertanggung jawab. Nilai Kepahlawanan dari I Gusti Ketut Jelantik dalam perang Jagaraga digunakan sebagai sumber penanaman karakter. Nilai kepahlawanan dari pahlawan ini dapat digunakan sebagai sumber penanaman karakter dalam pembelajaran IPS di SMP Laboratorium Undiksha Singaraja yang penerapannya dilakukan dengan menyesuaikan pada Kompetensi Dasar di dalam RPP yang digunakan dalam kegiatan pembelajaran.

Saran tersebut antara lain sebagai berikut: Untuk Guru IPS, guru dalam menyampaikan materi mampu untuk memanfaatkan aspek-aspek lokal, seperti kehidupan budaya, sosial, ekonomi, dan politik di lingkungan siswa berada. Untuk Siswa, siswa harus mengetahui bahwa selain pahlawan nasional mereka juga memiliki pahlawan lokal yang perannya tidak kalah penting dari pahlawan nasional. Untuk Masyarakat, tempat seperti monumen dan jalan-jalan bersejarah yang kaya akan nilai-nilai dan kebudayaan tersebut setidaknya harus diperhatikan.

\section{DAFTAR PUSTAKA}

Gunawan Rudy. 2013. Pendidikan IPS Filosof, Konsep dan Aplikasi. Bandung: Alfabeta.

Kartodirdjo, Sartono. 1973. Sejarah Perlawanan-perlawanan Terhadap Kolonialisme. Yogyakarta: Departemen Pertahanan Keamanan Pusat Sejarah ABRI.

Koesoema, Doni A. 2010. Pendidikan Karakter; Strategi mendidik Anak di Zaman Global. Jakarta: Grasindo

Pageh, I Made. 2011. Kepahlawanan dan Perjuangan Sejarah Sekitar Proklamasi Kemerdekaan Negara Kesatuan Republik Indonesia (Konteks Lampah Mr. I Gusti Ketut Pudja, 1908-2010).

Sastrodiwiryo, Soegianto. 2011. Perang Jagaraga (1846-1849). Denpasar: Pustaka Bali Post.

Tim Penyusun. 1980/1981. Sejarah Perang Jagaraga. Bali: Proyek APBD. Prop. Dati I.

Tim Penyusun. 1989/1990. Kepahlawanan Patih Agung I Gusti Ketut Jelantik Riwayat Hidup dan Perjuangannya. Bali: Proyek Penyusunan Naskah Perjuangan Patih Jelantik. 